\title{
1 High-throughput Identification of Eukaryotic Parasites and Arboviruses in Mosquitoes
}

\section{Running title: High-throughput Surveillance of Parasites and Viruses}

3

4 Matthew V. Cannon ${ }^{1}$, Haikel N. Bogale ${ }^{1}$, Devika Bhalerao ${ }^{1}$, Kalil Keita ${ }^{2}$, Denka Camara ${ }^{2}$, Yaya Barry ${ }^{2}$,

5 Moussa Keita ${ }^{2}$, Drissa Coulibaly ${ }^{3}$, Abdoulaye K. Kone ${ }^{3}$, Ogobara K. Doumbo ${ }^{3+}$, Mahamadou A. Thera ${ }^{3}$,

6 Christopher V. Plowe ${ }^{4}$, Mark A. Travassos ${ }^{4}$, Seth R. Irish ${ }^{5}$, Joshua Yeroshefsky ${ }^{6}$, Jeannine Dorothy ${ }^{7}$, Brian

$7 \quad$ Prendergast $^{7}$, Brandyce St. Laurent ${ }^{8}$, Megan L. Fritz ${ }^{6}$, David Serre ${ }^{1^{*}}$

8

$9{ }^{1}$ Institute for Genome Sciences, University of Maryland School of Medicine, Baltimore, MD, USA.

$10 \quad{ }^{2}$ Programme National de Lutte contre le Paludisme, Guinea.

$11{ }^{3}$ Malaria Research and Training Center, University Science, Techniques and Technologies of Bamako,

12 Mali.

$13{ }^{4}$ Malaria Research Program, Center for Vaccine Development and Global Health, University of Maryland

14 School of Medicine, Baltimore, USA.

$15{ }^{5}$ U.S. President's Malaria Initiative and Entomology Branch, Division of Parasitic Diseases and Malaria,

16 Center for Global Health, Centers for Disease Control and Prevention, Atlanta, USA.

$17{ }^{6}$ Department of Entomology, University of Maryland College Park, College Park, MD, USA.

$18{ }^{7}$ Mosquito Control Program, Maryland Department of Agriculture, Annapolis, MD, USA.

$19{ }^{8}$ Laboratory of Malaria and Vector Research, National Institute of Allergy and Infectious Diseases,

20 Rockville, MD, USA.

21 tDeceased

22

$23 *$ correspondence to $\underline{\text { dserre@som.umaryland.edu }}$

24 University of Maryland School of Medicine 
Institute for Genome Sciences

Department of Microbiology \& Immunology

27 HSFIII

29 Baltimore, MD 21201

Abbreviations: National Center for Parasitology, Entomology, and Malaria Control (CNM), American

31 Type Culture Collection (ATCC)

\section{Acknowledgements}

We wish to thank our collaborators at the National Center for Parasitology, Entomology, and Malaria

Malaria Research and Training Center, University of Science, Techniques and Technologies, Bamako,

Malaria Initiative, and all those participating in collections for support in the sample collection and processing in Guinea. The findings and conclusions in this report are those of the authors and do not necessarily represent the official position of the Centers for Disease Control and Prevention.

Conflict of interest statement:

42 The authors have stated explicitly that there are no conflicts of interest in connection with this article.

\section{Author contributions}

MVC, BSTL, MF and DS designed the study. BSTL, MF, KK, DC, YB, MK, DC, AKK, OKD, MAT, CVP, MT, SI, read and approved the final manuscript. 


\section{Abstract}

51 Vector-borne pathogens cause many human infectious diseases and are responsible for high mortality

52 and morbidity throughout the world. They can also cause livestock epidemics with dramatic social and

53 economic consequences. Due to the high costs, vector-borne disease surveillance is often limited to

54 current threats, and the investigation of emerging pathogens typically occur after the reports of clinical

55 cases. Here, we use high-throughput sequencing to detect and identify a wide range of parasites and

56 viruses carried by mosquitoes from Cambodia, Guinea, Mali and Maryland. We apply this approach to

57 individual Anopheles mosquitoes as well as pools of mosquitoes captured in traps; and compare the

58 outcomes of this assay when applied to DNA or RNA. We identified known human and animal pathogens

59 and mosquito parasites belonging to a wide range of taxa, insect Flaviviruses, and novel DNA sequences

60 from previously uncharacterized organisms. Our results also revealed that analysis of the content of an

61 entire trap is an efficient approach to monitor and identify potential vector-borne pathogens in large

62 surveillance studies, and that analyses of RNA extracted from mosquitoes is preferable, when possible,

63 over DNA-based analyses. Overall, we describe a flexible and easy-to-customize assay that can provide

64 important information for vector-borne disease surveillance and research studies to efficiently

65 complement current approaches.

66 Keywords: vector-borne pathogens, eukaryotic parasites, arbovirus, surveillance, zoonosis, emerging

67 pathogens 


\section{Introduction}

70 Different arthropods can, during a blood feeding, transmit viruses, protists and helminths to humans (1).

71 These organisms cause some of the most prevalent human infectious diseases, including malaria,

72 dengue, schistosomiasis or Chagas disease, and are responsible for more than 700,000 human deaths

73 worldwide every year (2-4). Vector-borne diseases are also responsible for some of the most alarming

74 recent epidemics in the western hemisphere, either due to the emergence of new pathogens (e.g., Zika

$75(5,6))$, the reemergence of historically important pathogens (e.g., Yellow Fever (7)) or the expansion of

76 diseases beyond their historical ranges (e.g., West Nile (8) and Chikungunya (7)). In addition to this

77 burden on human health, many vector-borne diseases affect domesticated animals (e.g., heartworms (9,

78 10)), livestock (e.g., Theileriosis $(11,12))$ and wild animals (e.g., avian malaria $(13,14))$. Some of these

79 animal diseases have dramatic economic consequences in endemic areas $(11,12)$, while others are

80 zoonotic diseases, further affecting human populations (15-20).

81 Efficient vector-borne disease surveillance is critical for reducing disease transmission and preventing

82 outbreaks. Past elimination campaigns for vector-borne diseases, usually targeting a specific human

83 pathogen, have often relied on entomological approaches such as widespread insecticide spraying and

84 disruption of larval habitats $(21,22)$. To be successful, such efforts need to be guided by detailed

85 knowledge of the parasites' and vectors' distributions. Unfortunately, current entomological

86 surveillance approaches are extremely resource-intensive: the collection of samples is time consuming

87 requiring trained personnel, vector species identification is laborious, and the detection of pathogens is

88 expensive since hundreds of mosquitoes typically need to be screened to identify a few infected ones.

89 Consequently, public health officials and vector biologists typically focus on monitoring only a few

90 specific pathogens associated with the most current threats. These constraints are particularly

91 problematic as they hamper the early detection of emerging pathogens and vector surveillance is often

92 implemented in response to reports of clinical cases rather than preventively. 
93 We have recently described a sequencing-based method using high-throughput amplicon sequencing to

94 detect known and previously uncharacterized eukaryotic parasites from biological samples in a

95 comprehensive, high-throughput and cost-efficient manner (23). Here, we present the application of this

96 approach to characterize eukaryotic parasites and arboviruses from more than 900 individual Anopheles

97 mosquitoes collected in Cambodia, Guinea and Mali, as well as from 25 pools of mosquitoes captured in

$98 \mathrm{CDC} \mathrm{CO}_{2}$-baited light traps in Maryland, USA. We also compare the performance of the assay when

99 screening DNA and RNA from the same samples. Overall, our study demonstrates how this sequencing-

100 based assay could significantly improve monitoring of human and animal vector-borne pathogens.

101

102 Methods

103 Samples

104 We analyzed a total of 930 individual mosquitoes, as well as 25 pools each containing 50-291 mosquitoes (2,589 total) (Table 1 and Supplemental Tables 1-3).

First, we analyzed DNA previously extracted from 265 individual Anopheles mosquitoes collected in the

107 Cambodian provinces of Pursat, Preah Vihear, and Ratanakiri (24). These mosquitoes were collected using cow- or human-baited tents, human landing collections, CDC light traps and barrier-screen fences and immediately preserved by desiccation upon collection. These 265 Anopheles mosquitoes represent 22 different species collected between July and August of 2013 (see Supplemental Table 1 for details).

111 Second, we included DNA samples from 81 individual mosquitoes collected in Bandiagara, Mali. DNA

112 from these samples was extracted using Chelex ${ }^{\circledast} 100$ (Bio-Rad) after incubation of bisected and 113 homogenized mosquitoes in $1 \%$ saponin in PBS.

114 Third, we extracted DNA from 584 individual Anopheles mosquitoes collected in six sites in Guinea and 115 preserved in ethanol immediately upon collection. These mosquitoes were collected by human landing 116 catch and pyrethrum spray (Supplemental Table 2). Each mosquito was homogenized in $200 \mu \mathrm{l}$ 
117 ATL/proteinase K solution using five RNase-free $1 \mathrm{~mm}$ zirconium oxide beads in a TissueLyser II for 12

118 minutes at $20 \mathrm{~m} / \mathrm{s}$. We centrifuged the solution at $2500 \mathrm{rpm}$ for three minutes and incubated them at

$11955^{\circ} \mathrm{C}$ for one hour. We performed a second homogenization step for four minutes at $20 \mathrm{~m} / \mathrm{s}$ followed by

120 a final incubation at $55^{\circ} \mathrm{C}$ overnight. We then isolated DNA using the Qiagen DNeasy 96 Blood \& Tissue

121 Kit according to the manufacturer's instruction and eluted DNA from each sample in $200 \mu \mathrm{l}$.

122 Finally, we analyzed 25 pools of mosquitoes collected throughout Prince George's county (Maryland,

123 USA) by the Maryland Department of Agriculture using $\mathrm{CO}_{2}$-baited light traps (Supplemental Table 3).

124 Each pool contains all mosquitoes from one light-trap ( 50-291 mosquitoes) and was stored at room

125 temperature for up to 24 hours before long-term storage at $-20^{\circ} \mathrm{C}$. We homogenized each pool of

126 mosquitoes using a Qiagen TissueLyser II with Teenprep Matrix D $15 \mathrm{ml}$ homogenization tubes (MP

127 Biomedicals) and isolated successively RNA and DNA from each sample using the RNeasy PowerSoil

128 Total RNA kit (Qiagen) with the RNeasy PowerSoil DNA Elution Kit and a final elution volume of $100 \mu$.

129 Evaluation of Arbovirus primers

130 We tested universal flavivirus primers retrieved from the literature (25) on West Nile $(n=3)$, Zika $(n=2)$

131 and Dengue $(n=2)$ viral RNAs obtained from the American Type Culture Collection (ATCC). We

132 synthesized cDNA from $2 \mu \mathrm{L}$ of RNA using M-MLV reverse transcriptase (Promega) and random

133 hexamers, and amplified the resulting cDNA with GoTaq ${ }^{\circledR}$ DNA polymerase (Promega) under the

134 following conditions: initial two-minute denaturing step at $95^{\circ} \mathrm{C}$ followed by 40 cycles of $95^{\circ} \mathrm{C}$ for 30

135 seconds, $50^{\circ} \mathrm{C}$ for 30 seconds and $72^{\circ} \mathrm{C}$ for 40 seconds. A final extension at $72^{\circ} \mathrm{C}$ for ten minutes was

136 followed by incubation at $4^{\circ} \mathrm{C}$. We ran the products on an agarose gel to determine whether each virus

137 RNA was amplifiable.

138 PCR amplification of pathogen nucleic acids before high-throughput sequencing 
First, we synthesized cDNA using M-MLV reverse transcriptase (Promega) and random hexamers from either 1) $2 \mu \mathrm{l}$ of the nucleic acids isolated from the Guinean mosquitoes (i.e., using RNA carried over during the DNA extraction), or 2) $3 \mu \mathrm{L}$ of RNA extracted from the pools of Maryland mosquitoes.

Then, we amplified DNA and cDNA (when available) from each sample, as well as from 176 no-DNA controls, with a total of 11 primer pairs, each targeting a specific taxon known to contain human pathogens (Table 2). For each primer pair, we amplified DNA and cDNA using GoTaq ${ }^{\circledR}$ DNA polymerase for 30 seconds, $50^{\circ} \mathrm{C}$ for 30 seconds and $72^{\circ} \mathrm{C}$ for 30 seconds. A final extension at $72^{\circ} \mathrm{C}$ for ten minutes was followed by incubation at $4^{\circ} \mathrm{C}$. All primers used in these taxon-specific PCRs included $5^{\prime}$-end tails to serve as priming sites for a second PCR. We then pooled all PCR products generated from one sample and performed a second PCR using primers targeting these tails to incorporate, at the end of each amplified molecule, i) a unique oligonucleotide "barcode" specific to each sample and ii) DNA sequences average of 12,703 paired-end reads of 251 or 301 bp per sample.

\section{Bioinformatic analyses}

We first separated the reads generated from each sample according to their unique barcodes and merged the overlapping ends of each read pair using PANDAseq (28) to generate consensus DNA sequences and correct sequencing errors (that disproportionally occur at the end of the reads). Note least $50 \mathrm{bp}$ between paired-end reads. All read pairs that did not merge correctly were discarded from

160 further analyses. We identified and trimmed the primer sequences from each read and eliminated all 
DNA sequences were obtained and how many reads carried each of these unique DNA sequences.

164 Sequences observed less than ten times in the entire dataset were omitted as they likely resulted from

165 PCR or sequencing errors (26). We then compared each unique DNA sequence to all sequences

166 deposited in the NCBI nt database using BLAST (29) and used custom pipelines

167 (https://github.com/MVesuviusC/2020MosquitoSurveillancePaper) to retrieve the taxonomic

168 information associated with the most similar sequence(s). For each sample, only sequences with at least

16910 reads and more than $70 \%$ identity with an annotated NCBI sequence over the entire sequence length

170 were further considered. This identity cutoff, while low, allows inclusion of results from highly

171 genetically divergent organisms which can then be scrutinized further. This is critical when identifying

172 species without closely related sequences available. If DNA sequences from multiple species were

173 equally similar to one of our sequences, we recorded all corresponding species names. Finally, we

174 summarized, for each mosquito, the parasite species or virus identified, the percentage identity

175 between the reads and the most similar NCBI sequence(s), and the number of reads supporting the

176 identification in this sample.

\section{Phylogenetic analyses}

178 To better characterize specific DNA sequences with ambiguous species identification, we analyzed these

179 sequences together with orthologous sequences from closely related species. Briefly, we used

180 PrimerTree (26) to retrieve NCBI orthologous DNA sequences from all species of the targeted taxon. We

181 aligned these sequences with the DNA sequence(s) amplified from the mosquito(es) using MAFFT (30)

182 and reconstructed neighbor-joining trees using MEGA (31) to estimate the phylogenetic position of the

183 amplified DNA sequences.

\section{Further determination of taxonomical assignments}


185 To improve species identification when multiple species had identical DNA sequences, or improve

186 phylogenetic analyses of unknown sequences, we amplified and sequenced specifically chosen DNA loci

187 from pathogens within the same mosquitoes.

188 For differentiating Theileria species, we used previously published primers (GGCGGCGTTTATTAGACC,

189 TCAATTCCTTTAAGTTTCAGCC) to amplify an informative portion of the 18S rRNA gene [31] using DNA

190 from 19 samples identified as Theileria positive by high-throughput sequencing. Amplification was

191 conducted under the following conditions: initial denaturing step at $95^{\circ} \mathrm{C}$ for two minutes followed by 40

192 cycles of $95^{\circ} \mathrm{C}$ for 30 seconds, $50^{\circ} \mathrm{C}$ for 30 seconds and $72^{\circ} \mathrm{C}$ for 40 seconds. A final extension at $72^{\circ} \mathrm{C}$ for

193 five minutes was followed by incubation at $4^{\circ} \mathrm{C}$. Since gel electrophoresis revealed off-target

194 amplification (multiple bands), we used a Pasteur pipette to collect a core from the agarose gel,

195 corresponding to the expected $900 \mathrm{bp} \mathrm{PCR}$ product, and dissolved it in $100 \mu \mathrm{l}$ of water at $60^{\circ} \mathrm{C}$ for 20

196 minutes. We then re-amplified $10 \mu \mathrm{l}$ of this DNA using 35 PCR cycles with the same conditions. After gel

197 electrophoresis, we treated the PCR reaction with $0.046 \mu \mathrm{l}$ of Exonuclease I (NEB) and $0.4625 \mu \mathrm{l}$ of

198 Shrimp alkaline phosphatase (Affymetrix) at $37^{\circ} \mathrm{C}$ for 30 minutes, with a final five-minute inactivation

199 step at $95^{\circ} \mathrm{C}$. We then Sanger sequenced each PCR product in both directions using the forward and

200 reverse primers. We manually trimmed the reads and merged them using Flash (32). We aligned the

201 reads, along with known Theileria sequences from the NCBI nucleotide database, using MAFFT $(30,33)$

202 and generated a neighbor joining tree with 500 bootstraps and plotted it in MEGA7 (34).

203 To identify the species of the filarial worms detected in two individual mosquitoes, we designed primers

204 to amplify a $3.5 \mathrm{~kb}$ portion of the mitochondrial DNA. Briefly, we downloaded all available filarial worm

205 (Filarioidea) mitochondrial sequences from the NCBI nucleotide database, aligned them, generated a

206 consensus sequence and designed primers using primer3 (35). We then used these primers

207 (TTCGTCGTGAGACAGAGCGG, AGGCCATTGACGGATGGTTTGTAC) to amplify DNA from the two positive

208 mosquitoes using the Expand ${ }^{\mathrm{TM}}$ Long Range dNTPack kit (Sigma) using the following conditions: initial 
denaturing step at $95^{\circ} \mathrm{C}$ for two minutes followed by 45 cycles of $92^{\circ} \mathrm{C}$ for 30 seconds, $55^{\circ} \mathrm{C}$ for 30 seconds and $68^{\circ} \mathrm{C}$ for five minutes. A final extension at $68^{\circ} \mathrm{C}$ for ten minutes was followed by incubation at $4^{\circ} \mathrm{C}$. We then performed a second PCR to add $10 \mathrm{bp}$ barcodes to the $5^{\prime}$ end of both forward and reverse primers to allow differentiating both samples after sequencing. The two barcodes differed by 8 and 7 bases for the forward and reverse primers, respectively, with no more than 2 identical bases in a row (Supplemental Table 4). For this second PCR, we used the following conditions: initial denaturing for five minutes. A final extension at $68^{\circ} \mathrm{C}$ for ten minutes was followed by incubation at $4^{\circ} \mathrm{C}$. We

217 purified the amplicons using AMPure XP beads (Beckman Coulter) (2:1 DNA:beads ratio) and then combined equimolar amounts of each barcoded PCR product before circular consensus sequencing on a

221 MEGA (36).

\section{Assessment of the dynamics of viral and mosquito RNA degradation}

223 To assess the dynamics of viral RNA degradation over time, we analyzed colony Culex pipiens mosquitoes known to carry Culex flavivirus. The colony was initiated from diapausing adult Culex pipiens

225 that were collected from Oak Lawn and Des Plaines, IL, on 2/8/10. These two collections were combined

226 to make one colony, which was determined to be Culex flavivirus positive according reverse 227 transcriptase PCR (25). We examined three pools of five mosquitoes for each condition (i.e., stored with no preservative, in ethanol or in RNAlater (Invitrogen)) and at each time point (i.e., fresh, after twoweek or after four-week storage at room temperature). After 0, 2 or 4 weeks at room temperature, the mosquitoes were stored at $-80^{\circ} \mathrm{C}$ until RNA isolation. We isolated RNA from each pool of mosquitoes 
232 (Promega) with random hexamers for PCRs using Culex primers and, separately, on $2 \mu$ of RNA for PCRs

233 using flavivirus primers.

234 For each pool of 5 Culex mosquitoes from the Culex flavivirus-infected colony, we performed 235 quantitative reverse transcriptase PCR (qRT-PCR) to quantify the amount of mosquito and viral RNAs 236 using the primers Culex_flavivirus_3F (TGCGAARGATCTDGAAGGAG) - Culex_flavivirus_3R 237 (CACGCACAACAAGACGATRA) targeting the virus sequence, and Culicinae_Cox1_379_F 238 (AYCCHCCTCTTTCATCTGGA) - Culicidae_Cox1_670_R (CCTCCTCCAATTGGRTCAAAG) targeting mosquito 239 RNA. We used Perfecta SYBR green PCR mastermix (Quantabio) with the following conditions: initial 15240 minute denaturing step at $95^{\circ} \mathrm{C}$ followed by 40 cycles of $95^{\circ} \mathrm{C}$ for 30 seconds, $55^{\circ} \mathrm{C}$ (Culex primers) or $24150^{\circ} \mathrm{C}$ (flavivirus primers) for 30 seconds and $72^{\circ} \mathrm{C}$ for one minute (Culex primers) or 40 seconds (flavivirus 242 primers). We performed standard cycle threshold and melt curve analysis afterwards using default 243 settings.

\section{Results}

246 Amplicon sequencing for high-throughput characterization of microorganisms in mosquitoes

247 We analyzed 265 Anopheles mosquitoes collected in Cambodia, 665 Anopheles mosquitoes collected in 248 Guinea and Mali as well as the content of 25 light traps, each containing 50-291 mosquitoes, collected in 249 Maryland, USA. We screened each sample for a wide range of eukaryotic parasites using 10 primer sets 250 designed to amplify DNA from all species of the taxa known to include human pathogens: 251 Apicomplexans, Kinetoplastids, Parabasalids, nematodes, Platyhelminthes and Microsporidians (Table 252 2). We also screened RNA extracted from the individual African Anopheles and from the pools of 253 mosquitoes from Maryland for flaviviruses (see Materials and Methods, Table 2). After taxon-specific 254 amplification, we pooled all PCR products generated from the same mosquito together, barcoded them 255 and sequenced all libraries to generate an average of 12,703 paired-end reads per sample 
256 (Supplemental Figure 1). After merging read pairs, stringent quality filters and removal of the products

257 of off-target amplification (e.g., Anopheles and bacteria DNA sequences), we obtained 61,177 unique

258 DNA sequences, each represented by ten reads or more, and accounting in total for $6,796,105$ reads

259 (Supplemental Table 5). These sequences were amplified with all primers and from a total of 185

260 samples: 42 out of 265 Cambodian mosquitoes (16\%), 120 out of 665 African mosquitoes (18\%), and 23

261 out of the 25 pools (92\%) of mosquitoes collected in Maryland were positive for at least one of the taxa

262 tested. On average, each sequence was supported by 1,306 reads per sample (range: 10-43,440). By

263 contrast, out of 176 negative controls, only $12(7 \%)$ yielded any sequence from the targeted taxa and

264 those were represented by 213 reads on average (range: 10-3,539).

\section{Identification of eukaryotic parasites}

266 We retrieved DNA sequences identical to sequences previously amplified from Theileria parasites from

26722 African and 15 Cambodian mosquitoes, as well as from seven of the Maryland traps. Theileria

268 sequences were successfully amplified with both the Apicomplexa and Eimeronia primer pairs. All

269 samples positive for Theileria with the Eimeronia primers were also positive with the Apicomplexa

270 primers. On the other hand, the Eimeronia primers provided sufficient information to assign each

271 sequence to a single species, while the sequences amplified with Apicomplexa primers were unable to

272 differentiate among the Theileria species (see also below). We detected sequences identical to

273 Plasmodium falciparum in eight African samples and two Cambodian samples, while sequences most

274 similar (82.0\%-99.5\% identity) to bird Plasmodium species were amplified from 20 of the 25 traps in

275 Maryland (Table 3). We also amplified a sequence that was identical to several Babesia species (100\%

276 identity) in one trap by two different primer pairs. Finally, we detected DNA from a known

277 apicomplexan parasite of mosquitoes, Ascogregarina barretti (37), in two of the traps.

278 From all individual mosquitoes, only one Cambodian Anopheles yielded a Kinetoplast sequence that was

279 most similar to Strigomonas culicis (96.9\% identity). By contrast, 22 of the traps were positive for 
Kinetoplasts, yielding sequences similar to sequences from Angomonas, Blastocrithidia, Blechomonas,

\section{7\% identity) (Table 3).}

284 Many sequences were amplified using the Microsporidia primers: 72 African mosquitoes were positive with sequences similar or identical to Culicospora, Encephalitozoon, Hazarida, Microsporidium and

traps also yielded Microsporidia sequences closely matching those of Amblyospora, Andreanna,

Regarding parasites from the Parabasalia group, four African mosquitoes were positive for

291 Tetratrichomona, Trichomonas or Tritrichomonas with high sequence similarity (94.8\%-100\%) while a

292 single Cambodian mosquito was positive for Trichomitus (98.7\% identity). No Parabasalia were detected

293 in the Maryland traps.

294 We detected Platyhelminthes sequences in four African mosquitoes, all similar to Schistosoma mansoni 295 (92.1\%-100\% identity). Three Cambodian mosquitoes yielded sequences most similar to those of either 296 Pleurogenoides or Pleurogenes (94.9\%-95.4\% identity). Three traps in Maryland were positive for 297 Platyhelminthes, with sequences most similar to Haematoloechus (98.7\% identity).

298 The taxonomic resolution of the nematode primers was lower than that of the other taxon-specific 299 primer pairs and the amplified sequences often matched multiple species (or even genera). We 300 amplified nematode sequences from 33 African Anopheles, including sequences most similar to 301 Abursanema, Acanthocheilonema, Auanema, Caenorhabditis, Dipetalonema, Filarioidea, Loa, 302 Loxodontofilaria, Madathamugadia, Onchocerca, Pelecitus, Setaria or Trichuris, although the sequence 303 similarity (95.3-100\%) clearly indicated that, in some cases, the exact identity of the species was 
unknown (see also below). Ten Cambodian mosquitoes were positive for Setaria digitata (100\% identity)

while other mosquitoes yielded sequences that matched Setaria and one or more of the following

genera: Aproctella, Breinlia, Dipetalonema, Dirofilaria, Loa, Loxodontofilaria, Madathamugadia,

Onchocerca, Pelecitus. Nineteen different traps from Maryland produced nematode sequences with particularly high read counts of Setaria, Yatesia and Dirofilaria sequences ( $98.9 \%$ - 100\% identity). Other

genera detected in the traps included Acanthocheilonema, Aproctella, Cercopithifilaria, Choriorhabditis,

Dipetalonema, Elaeophora, Filarioidea, Loa, Loxodontofilaria, Onchocercidae.

311 Overall, using this single assay, we screened over 3,500 mosquitoes from three geographic locations and identified DNA sequences from numerous microorganisms encompassing six classes, 12 orders and 23 families (Table 3).

\section{Identification of Flaviviruses in mosquitoes}

315 To detect and identify flaviviruses, we used a primer pair predicted in silico to amplify a wide range of mosquitoes, three were positive for viruses most similar to Anopheles flavivirus variants 1 and 2 (87.2\%most similar to the Calbertado and Nienokoue flaviviruses, although the percent identity was very low

322 (71.1\%-74.3\%) and they clearly separated from those viruses in phylogenetic analysis (Figure 1 and

323 Supplemental Figure 2). These sequences likely derive from viruses that have not been sequenced yet 324 but, since that they cluster with other mosquito flaviviruses (Figure 1 and Supplemental Figure 2), it is 325 likely that they represent mosquito-infecting viruses rather than new human pathogens.

326 One limitation of our study is that the mosquitoes collected in Maryland, USA were, as typical in many 327 entomological surveys, stored at room temperature upon collection which might have affected RNA 
preservation. To assess the stability of viral and mosquito RNA in samples stored at room temperature,

we kept pools of colony mosquitoes known to be infected with Culex flavivirus at room temperature for

\section{Follow-up phylogenetic studies}

339 The taxon-specific primers used in the high-throughput sequencing assay were designed to amplify all

members of the chosen group while avoiding off-target amplification and providing as much taxonomic

342 (to be sequenceable on a massively parallel sequencer) sometimes limits their resolution.

343 Thus, the Apicomplexa primers amplified multiple Theileria sequences but did not distinguish among species. We therefore amplified a longer DNA sequence (900 bp) of the $18 \mathrm{~S}$ rRNA locus from the

345 Theileria-positive African and Cambodian mosquitoes and sequenced them using Sanger sequencing 346 technology. Phylogenetic analysis of these longer sequences, together with known Theileria species 347 sequences deposited in NCBI, showed that the parasites amplified from the Cambodian mosquitoes 348 were closely related to $T$. sinensis, while those from African mosquitoes were most closely related to $T$. 349 velifera and T. mutans (Figure 2).

350 We also detected, in several African mosquitoes, filarial worm sequences whose taxonomic assignment 351 was uncertain. One sequence was $100 \%$ identical to both Loa loa and Dipetalonema sp. YQ-2006 (also 
352 known as Mansonella) while the sequence obtained from the same mosquitoes using a different primer

353 pair was also most similar to Dipetalonema (Mansonella) but with $99.2 \%$ identity. To clarify the

354 taxonomy of these sequences, we used PacBio long read technology to sequence $3.5 \mathrm{~kb}$ of filarial worm

355 mitochondrial DNA (amplified by long range PCR from these two mosquitoes). We compared these

356 sequences to known filarial worm mitochondrial DNA sequences and found that these were most similar

357 to, but distinct from, Mansonella perstans (94 and 96 nucleotide differences or $97.0 \%$ identity), while

358 Loa loa was much more distantly related ( 83.3\% identity) (Figure 3). The genetic distance between

359 Mansonella perstans and Loa loa in this tree was much higher (519 nucleotide differences, 83.5\%

360 identity) than using short amplicon data where these two sequences were identical, providing greater

361 confidence in the phylogenetic analysis. We concluded that the filarial worms are most likely either

362 Mansonella perstans or a very closely related species.

363 Analysis of individual vs pooled mosquitoes

364 We analyzed both individual mosquitoes and pools of 50-291 mosquitoes. For the pools, 23 out of the

36525 produced sequences demonstrating that the amplification of pools of up to 291 mosquitoes is

366 feasible without significant PCR inhibition. Out of the 930 individual mosquitoes, $162(17.4 \%)$ had at

367 least ten reads from one or more parasites or arboviruses. By comparison, 23 out of the 25 traps (92\%)

368 yielded such sequences, meaning that fewer samples needed to be screened to detect pathogens when

369 samples were pooled. Note however that the individual mosquitoes and the CDC traps were not

370 collected from the same geographic locations and this could possibly cofound the results described.

\section{Analysis of DNA vs. RNA extracted from the same mosquito traps}

372 All primers used for detecting parasites and viruses are located within single-exon genes and can amplify

373 either DNA or cDNA with the same efficiency. However, the PCRs target genes that are typically highly

374 expressed (e.g., ribosomal RNA genes) and we would therefore expect many more copies of RNA than

375 DNA per cell, (although this could be diminished by the faster degradation of RNA molecules compared 
to DNA). To evaluate the relative sensitivity of our assay for screening DNA and RNA, we compared the

377 results obtained by analyzing matched DNA and RNA isolated from the same mosquito pools. We found

378 that for Spirurida, Kinetoplast, Microsporidia and Plasmodium PCR assays, $62.2 \%$ of the sequences

379 identified were detected only in the cDNA sample and not in the corresponding DNA sample from the

380 same trap. For those cases where a sequence was detected in both cDNA and DNA from a given trap,

381 the cDNA yielded more reads in 89 of 119 instances (with, on average, 24.5-fold more reads). Read

382 counts were higher in the DNA for only 29 of 119 cases with an average fold difference of 2.8 (one had

383 equal read counts in cDNA and DNA). Out of these 29 cases, $22(75.9 \%)$ of the sequences were most

384 similar to Trypanosoma species despite these sequences representing only 17.4 of all sequences. On

385 average, the cDNA samples produced $258-1,169$ more reads per hit than the matching DNA samples

386 (Figure 3), despite the storage of the samples at room temperature without preservative for more than

38724 hours.

\section{Discussion}

390 Vector-borne disease surveillance is an essential component of infectious disease control as it can

enable rapid detection of outbreaks and guide targeted elimination efforts (e.g., through insecticide

spraying). However, current approaches are extremely demanding in regards to human and financial

resources, both for the sample collection and the identification of potential pathogens. Consequently,

public health officials and vector biologists often have to focus on a handful of parasites associated with

397 high risk of failing to detect emerging pathogens until they cause outbreaks. Here, we describe 
human and animal diseases, as well as of parasites of the vector that could potentially be useful as biological controls.

401 The analyses of several hundred mosquitoes collected in Cambodia, Mali, Guinea and Maryland revealed well-known human pathogens including $P$. falciparum, which was the target of the initial study of the

403 Cambodian samples (24). In addition, we detected Theileria species and Setaria digitata, which cause 404 livestock diseases in Southeast Asia (38-42). While we were initially unable to conclusively determine the exact Theileria species with our initial assay, targeted follow-up studies using longer amplicons and Sanger sequencing (Figure 2 ) revealed that the sequences amplified from the African mosquitoes were most closely related to T. velifera and T. mutans, which are both known to infect African cattle (43), whereas the Cambodian mosquitoes carried sequences most closely related to $T$. sinensis, a species that infects cattle in China (44).

Theileria parasites are transmitted by ticks, not mosquitoes, and the DNA sequences recovered likely derive from parasites taken up by the mosquitoes during a blood meal but likely not transmissible to another hosts. The Schistosoma species detected in mosquitoes from Africa also likely result from parasites present in a bloodmeal. In this regard, it is interesting to note that when one considers the samples collected in Maryland and analyzed with both DNA and RNA, the read counts (a proxy for the

415 abundance of extracted molecules) for transmissible parasites (e.g., Plasmodium) or parasites of the 416 mosquitoes (e.g., Crithidia, Strigomonas and Takaokaspora) were typically higher in the RNA samples 417 than in the matched DNA samples while the opposite was true for parasites "sampled" during the blood 418 meal but unlikely to develop in Anopheles mosquitoes (e.g., Theileria, Trypanosoma) (Figure 4, 419 Supplemental Figure 4 and Supplemental Table 6). We speculate that this difference is due to the 420 difference between developing, live, parasites still synthesizing RNA molecules and dead (possibly 421 digested) parasites for which the RNA is slowly being degraded. Comparison of DNA and RNA from the 
422 same mosquito could perhaps provide a tool to differentiate transmissible parasites from those sampled

423 by the vector.

424 We also identified, in two African mosquitoes, sequences similar to known filarial worms but identical to

425 multiple sequences present in the database. Using this information, we characterized longer DNA

426 sequences and showed that these two mosquitoes likely carried Mansonella perstans parasites. Since

427 the PCR primers are designed to amplify any member of the selected taxa, they can reveal the presence

428 of novel pathogens as long as they are phylogenetically related to known parasites. This feature is a key

429 advantage of our assay for vector-borne disease surveillance as it may enable early detection of

430 emerging pathogens and zoonoses and provide a basis for rapid response.

431 In addition to known human parasites and potential emerging pathogens, this single-stop assay also

432 provides another source of information valuable for vector-borne disease control: $9 \%$ of the individual

433 mosquitoes and $62 \%$ of pooled mosquito samples screened yielded sequences of microsporidians

434 related to well-characterized arthropod parasites, which could potentially be used to guide the

435 development of targeted biological vector control. This ability to detect multiple parasites at once in a

436 high-throughput manner and across a wide range of taxonomical groups could reduce duplication of

437 collection efforts and costs, as mosquitoes collected for one purpose could be screened for many

438 parasites affecting both humans and animals. In addition, comprehensive characterization of the

439 parasites present in a given mosquito may also improve our understanding of the general factors

440 regulating infection and transmission: several studies have shown that immunity and previous infections

441 can influence the response of mosquitoes to human parasites and their transmission (45-47) and

442 information of current infections of wild-caught mosquitoes could, for example, significantly improve

443 our assessment of their vector capacity.

444 Several of the infectious diseases that have recently caused major public health challenges by spreading 445 outside of their typical range $(7,8)$ or emerging as novel human infectious diseases $(5,6)$, are caused by 
viruses transmitted by mosquitoes. We therefore extended our assay to capture, using the same

447 approach as for eukaryotic parasites, both known and novel flaviviruses. Since flaviviruses are RNA

448 viruses and RNA degrades much faster than DNA, we first examined how nucleic acid degradation

449 influenced our ability to detect virus over time. To test RNA preservation, we collected mosquitoes

450 known to carry Culex flavivirus and isolated RNA from pools of five mosquitoes, either immediately

451 frozen or kept at room temperature for two or four weeks, with either no preservative, ethanol or

452 RNAlater. The mosquitoes stored in preservatives had minimal loss of viral (and mosquito) RNAs as

453 determined by qRT-PCR (Supplemental Figure 3). Even when stored without preservatives, viral RNA

454 were detectable after 4 weeks at room temperature (although with a reduction of, on average, 10.7 PCR

455 cycles), demonstrating a remarkable stability of the RNA, possibly due to protection provided by the

456 viral capsid (by contrast very little mosquito RNA remained amplifiable after two weeks at room

457 temperature, Supplemental Figure 3). As a proof-of-principle and to demonstrate the potential of this

458 approach for viral disease surveillance, we screened the Maryland mosquito pools and the individual

459 African mosquitoes for flaviviruses. We identified several viruses, distinct from known viruses (Figure 1)

460 and, based on their phylogenic position, likely to infect mosquitoes rather than humans.

461 Based on the results described above, we believe that this single high-throughput assay can provide a

462 wide range of information critical for vector-borne disease researchers and public health officials.

463 However, several limitations need to be noted. One caveat is that, whereas false positive detection of a

464 species is highly unlikely (aside from laboratory cross-contamination), several factors could lead to false

465 negatives. Thus, while the primers were designed to amplify all known sequences of a given taxon as

466 effectively as possible, nucleotide differences at the primer binding sites could prevent efficient

467 amplification of a specific species. This potential problem could be particularly problematic if several

468 related parasites are present in the same sample but are differentially amplified: for example, it could

469 be possible that a Plasmodium parasite might be mis-detected if the sequences generated by an 
471 nucleic acids in one sample could also lead to false negatives. False negatives could also occur for

472 stochastic reasons: if only a few parasite cells are present in one sample (e.g., an Anopheles mosquito

473 infected by a Plasmodium ookinete) it is possible that no DNA will be present in the PCR reaction

474 (especially if the extract gets divided across many reactions). One approach to circumvent this limitation 475 could be to test cDNA instead of DNA $(48,49)$ : our analyses of the Maryland mosquitoes showed that,

476 for many primer sets, amplification of cDNA resulted in higher read counts than amplification of DNA

477 extracted from the same samples, despite the sub-optimal preservation of these samples. Another

478 limitation is the specificity of taxonomic assignment. As discussed above, if the sequenced amplicon

479 does not contain enough information to distinguish similar species, subsequent experiments may be

480 required to confirm pathogen identity for important detection events.

481 Finally, we showed that analyses of fairly large pools of mosquitoes (up to 300 mosquitoes) were 482 possible with our assay. This feature could be extremely useful in specific situations, such as for 483 efficiently detecting emerging pathogens, monitoring the spread of pathogens into new regions, or for 484 validating the success of elimination control programs.

\section{Conclusion}

487 This study demonstrates how our high-throughput, one-stop assay could efficiently complement current 488 toolkits to prevent vector-borne diseases by providing a comprehensive description of known and 489 emerging human viruses and parasites, informing on animal pathogens that could affect a region's 490 economy, and indicating possible biological control candidates that could be used against these disease 491 vectors. One additional feature of this sequencing-based assay is the ease of customizing it to different 492 settings and research questions. Since the assay relies on PCR primers, it is straightforward to add and 
remove primers for specific taxa of interest, or to combine them with additional PCRs to characterize,

494 for example, the source of the blood meal (27).

495 Acknowledgements

496 We wish to thank our collaborators at the National Center for Parasitology, Entomology, and Malaria

497 Control (CNM) in Phnom Penh, Stop Palu and the National Malaria Control Program in Guinea and at the 498 Malaria Research and Training Center, University of Science, Techniques and Technologies, Bamako, 499 Mali for their help with the sample collection and processing, as well as Erin Haser, Rachel Koch, Jessica 500 Moskowitz, Rachel Shuck, and Elizabeth Allan. We also thank Stop Palu (RTI), the U.S. President's 501 Malaria Initiative, and all those participating in collections for support in the sample collection and 502 processing in Guinea. The findings and conclusions in this report are those of the authors and do not 503 necessarily represent the official position of the Centers for Disease Control and Prevention.

\section{Conflict of interest statement:}

505 The authors have stated explicitly that there are no conflicts of interest in connection with this article.

\section{Author contributions}

507 MVC, BSTL, MF and DS designed the study. BSTL, MF, KK, DC, YB, MK, DC, AKK, OKD, MAT, CVP, MT, SI, 508 JD and BP collected and/or provided access to the mosquito samples. MVC, HB, BSTL and DB performed 509 the laboratory experiments. MVC analyzed the data. MVC and DS prepared the manuscript. All authors 510 read and approved the final manuscript.

\section{Availability of data and material}

512 The datasets generated for the current study are available in the NCBI SRA repository (Accession 513 numbers SRR12797126 - SRR12797220, SRR12797360 - SRR12797683, SRR12796164 - SRR12796923 and 514 SAMN16182375 - SAMN16183134)

\section{$515 \quad$ Funding}


bioRxiv preprint doi: https://doi.org/10.1101/2021.01.12.426319; this version posted January 14, 2021. The copyright holder for this preprint (which was not certified by peer review) is the author/funder, who has granted bioRxiv a license to display the preprint in perpetuity. It is made available under aCC-BY 4.0 International license.

516 This study was supported by DS and by the Intramural Research Program (NIAID-NIH) to BSTL. SRI was

517 funded by the U.S. President's Malaria Initiative.

518 


\section{References}

5201 1. Ecker, D. J., Sampath, R., Willett, P., Wyatt, J. R., Samant, V., Massire, C., Hall, T. A., Hari, K.,

521

522

523

524

525

526

527

528

529

530

531

532

533

534

535

536

537

538

539

540

541

542

543

544

545

546

547

548

549

550

551

552

553

554

555

556

557

558

559

560

561

562

563

564

565 McNeil, J. A., Buchen-Osmond, C., and Budowle, B. (2005) The Microbial Rosetta Stone Database: a compilation of global and emerging infectious microorganisms and bioterrorist threat agents. BMC microbiology 5, 19

2. WHO. (2017) Vector-borne diseases. In Fact sheet (Organization, W. H., ed)

3. (2008) In Vector-Borne Diseases: Understanding the Environmental, Human Health, and Ecological Connections, Workshop Summary, Washington (DC)

4. Collaborators, G. B. D. M. (2018) Global, regional, and national age-sex-specific mortality and life expectancy, 1950-2017: a systematic analysis for the Global Burden of Disease Study 2017. Lancet 392, 1684-1735

5. Gorshkov, K., Shiryaev, S. A., Fertel, S., Lin, Y. W., Huang, C. T., Pinto, A., Farhy, C., Strongin, A. Y., Zheng, W., and Terskikh, A. V. (2018) Zika Virus: Origins, Pathological Action, and Treatment Strategies. Frontiers in microbiology 9, 3252

6. Liu, Z. Y., Shi, W. F., and Qin, C. F. (2019) The evolution of Zika virus from Asia to the Americas. Nat Rev Microbiol 17, 131-139

7. Higuera, A., and Ramirez, J. D. (2019) Molecular epidemiology of dengue, yellow fever, Zika and Chikungunya arboviruses: An update. Acta Trop. 190, 99-111

8. Sejvar, J. J. (2016) West Nile Virus Infection. Microbiol Spectr 4

9. McCall, J. W., Genchi, C., Kramer, L. H., Guerrero, J., and Venco, L. (2008) Heartworm disease in animals and humans. Adv. Parasitol. 66, 193-285

10. Otranto, D., Dantas-Torres, F., Brianti, E., Traversa, D., Petric, D., Genchi, C., and Capelli, G. (2013) Vector-borne helminths of dogs and humans in Europe. Parasit Vectors 6, 16

11. Nene, V., Kiara, H., Lacasta, A., Pelle, R., Svitek, N., and Steinaa, L. (2016) The biology of Theileria parva and control of East Coast fever - Current status and future trends. Ticks Tick Borne Dis 7, 549-564

12. Gachohi, J., Skilton, R., Hansen, F., Ngumi, P., and Kitala, P. (2012) Epidemiology of East Coast fever (Theileria parva infection) in Kenya: past, present and the future. Parasit Vectors 5, 194

13. Clark, N. J., Clegg, S. M., and Lima, M. R. (2014) A review of global diversity in avian haemosporidians (Plasmodium and Haemoproteus: Haemosporida): new insights from molecular data. Int. J. Parasitol. 44, 329-338

14. Lapointe, D. A., Atkinson, C. T., and Samuel, M. D. (2012) Ecology and conservation biology of avian malaria. Ann. N. Y. Acad. Sci. 1249, 211-226

15. Cox-Singh, J., Davis, T. M., Lee, K. S., Shamsul, S. S., Matusop, A., Ratnam, S., Rahman, H. A., Conway, D. J., and Singh, B. (2008) Plasmodium knowlesi malaria in humans is widely distributed and potentially life threatening. Clin. Infect. Dis. 46, 165-171

16. Daneshvar, C., William, T., and Davis, T. M. E. (2018) Clinical features and management of Plasmodium knowlesi infections in humans. Parasitology 145, 18-31

17. White, N. J. (2008) Plasmodium knowlesi: the fifth human malaria parasite. Clin. Infect. Dis. 46, 172-173

18. Brasil, P., Zalis, M. G., de Pina-Costa, A., Siqueira, A. M., Junior, C. B., Silva, S., Areas, A. L. L., Pelajo-Machado, M., de Alvarenga, D. A. M., da Silva Santelli, A. C. F., Albuquerque, H. G., Cravo, P., Santos de Abreu, F. V., Peterka, C. L., Zanini, G. M., Suarez Mutis, M. C., Pissinatti, A., Lourenco-de-Oliveira, R., de Brito, C. F. A., de Fatima Ferreira-da-Cruz, M., Culleton, R., and Daniel-Ribeiro, C. T. (2017) Outbreak of human malaria caused by Plasmodium simium in the Atlantic Forest in Rio de Janeiro: a molecular epidemiological investigation. Lancet Glob Health 5, e1038-e1046 
19. McCarthy, J., and Moore, T. A. (2000) Emerging helminth zoonoses. Int. J. Parasitol. 30, 13511360

20. Cutler, S. J., Fooks, A. R., and van der Poel, W. H. (2010) Public health threat of new, reemerging, and neglected zoonoses in the industrialized world. Emerg. Infect. Dis. 16, 1-7

21. Benelli, G., and Beier, J. C. (2017) Current vector control challenges in the fight against malaria. Acta Trop. 174, 91-96

22. Walker, K., and Lynch, M. (2007) Contributions of Anopheles larval control to malaria suppression in tropical Africa: review of achievements and potential. Med. Vet. Entomol. 21, 221

23. Cannon, M. V., Bogale, H., Rutt, L., Humphrys, M., Korpe, P., Duggal, P., Ravel, J., and Serre, D. (2018) A high-throughput sequencing assay to comprehensively detect and characterize unicellular eukaryotes and helminths from biological and environmental samples. Microbiome 6, 195

24. St Laurent, B., Oy, K., Miller, B., Gasteiger, E. B., Lee, E., Sovannaroth, S., Gwadz, R. W., Anderson, J. M., and Fairhurst, R. M. (2016) Cow-baited tents are highly effective in sampling diverse Anopheles malaria vectors in Cambodia. Malar J 15, 440

25. Patel, P., Landt, O., Kaiser, M., Faye, O., Koppe, T., Lass, U., Sall, A. A., and Niedrig, M. (2013) Development of one-step quantitative reverse transcription PCR for the rapid detection of flaviviruses. Virol J 10, 58

26. Cannon, M. V., Hester, J., Shalkhauser, A., Chan, E. R., Logue, K., Small, S. T., and Serre, D. (2016) In silico assessment of primers for eDNA studies using PrimerTree and application to characterize the biodiversity surrounding the Cuyahoga River. Scientific reports 6, 22908

27. Logue, K., Keven, J. B., Cannon, M. V., Reimer, L., Siba, P., Walker, E. D., Zimmerman, P. A., and Serre, D. (2016) Unbiased Characterization of Anopheles Mosquito Blood Meals by Targeted High-Throughput Sequencing. PLoS Negl Trop Dis 10, e0004512

28. Masella, A. P., Bartram, A. K., Truszkowski, J. M., Brown, D. G., and Neufeld, J. D. (2012) PANDAseq: paired-end assembler for illumina sequences. BMC bioinformatics 13, 31

29. Altschul, S. F., Gish, W., Miller, W., Myers, E. W., and Lipman, D. J. (1990) Basic local alignment search tool. J. Mol. Biol. 215, 403-410

30. Katoh, K., and Standley, D. M. (2013) MAFFT multiple sequence alignment software version 7: improvements in performance and usability. Mol. Biol. Evol. 30, 772-780

31. Tamura, K., Stecher, G., Peterson, D., Filipski, A., and Kumar, S. (2013) MEGA6: Molecular Evolutionary Genetics Analysis version 6.0. Mol. Biol. Evol. 30, 2725-2729

32. Magoc, T., and Salzberg, S. L. (2011) FLASH: fast length adjustment of short reads to improve genome assemblies. Bioinformatics 27, 2957-2963

33. Katoh, K., Rozewicki, J., and Yamada, K. D. (2017) MAFFT online service: multiple sequence alignment, interactive sequence choice and visualization. Brief Bioinform

34. Kumar, S., Stecher, G., and Tamura, K. (2016) MEGA7: Molecular Evolutionary Genetics Analysis Version 7.0 for Bigger Datasets. Mol. Biol. Evol. 33, 1870-1874

35. Untergasser, A., Cutcutache, I., Koressaar, T., Ye, J., Faircloth, B. C., Remm, M., and Rozen, S. G. (2012) Primer3--new capabilities and interfaces. Nucleic Acids Res 40, e115

36. Kumar, S., Stecher, G., Li, M., Knyaz, C., and Tamura, K. (2018) MEGA X: Molecular Evolutionary Genetics Analysis across Computing Platforms. Mol. Biol. Evol. 35, 1547-1549

37. Siegel, J. P., Novak, R. J., and Maddox, J. V. (1992) Effects of Ascogregarina barretti (Eugregarinida: Lecudinidae) infection on Aedes triseriatus (Diptera: Culicidae) in Illinois. J. Med. Entomol. 29, 968-973 
38. Nakano, H., Tozuka, M., Ikadai, H., Ishida, H., Goto, R., Kudo, N., Katayama, Y., Muranaka, M., Anzai, T., and Oyamada, T. (2007) Morphological survey of bovine Setaria in the abdominal cavities of cattle in Aomori and Kumamoto Prefectures, Japan. J. Vet. Med. Sci. 69, 413-415

39. Weerasooriya, G., Sivakumar, T., Lan, D. T., Long, P. T., Takemae, H., Igarashi, I., Inoue, N., and Yokoyama, N. (2016) Epidemiology of bovine hemoprotozoa parasites in cattle and water buffalo in Vietnam. J. Vet. Med. Sci. 78, 1361-1367

40. Bawm, S., Shimizu, K., Hirota, J., Tosa, Y., Htun, L. L., Maw, N. N., Thein, M., Kato, H., Sakurai, T., and Katakura, K. (2014) Molecular prevalence and genetic diversity of bovine Theileria orientalis in Myanmar. Parasitol Int 63, 640-645

41. Liu, G. H., Li, J. Y., and Zhu, X. Q. (2017) Characterization of the complete mitochondrial genome of Setaria digitata (Nematoda: Setariidae) from China. J. Helminthol. 91, 772-776

42. Shin, S. S., Cho, K. O., and Wee, S. H. (2002) Ocular infection of cattle with Setaria digitata. J. Vet. Med. Sci. 64, 7-10

43. Mans, B. J., Pienaar, R., and Latif, A. A. (2015) A review of Theileria diagnostics and epidemiology. Int J Parasitol Parasites Wildl 4, 104-118

44. Liu, A., Guan, G., Liu, Z., Liu, J., Leblanc, N., Li, Y., Gao, J., Ma, M., Niu, Q., Ren, Q., Bai, Q., Yin, H., and Luo, J. (2010) Detecting and differentiating Theileria sergenti and Theileria sinensis in cattle and yaks by PCR based on major piroplasm surface protein (MPSP). Exp. Parasitol. 126, 476-481

45. Cirimotich, C. M., Dong, Y., Garver, L. S., Sim, S., and Dimopoulos, G. (2010) Mosquito immune defenses against Plasmodium infection. Dev. Comp. Immunol. 34, 387-395

46. Bian, G., Joshi, D., Dong, Y., Lu, P., Zhou, G., Pan, X., Xu, Y., Dimopoulos, G., and Xi, Z. (2013) Wolbachia invades Anopheles stephensi populations and induces refractoriness to Plasmodium infection. Science 340, 748-751

47. Meister, S., Kanzok, S. M., Zheng, X. L., Luna, C., Li, T. R., Hoa, N. T., Clayton, J. R., White, K. P., Kafatos, F. C., Christophides, G. K., and Zheng, L. (2005) Immune signaling pathways regulating bacterial and malaria parasite infection of the mosquito Anopheles gambiae. Proc. Natl. Acad. Sci. U. S. A. 102, 11420-11425

48. Kamau, E., Tolbert, L. S., Kortepeter, L., Pratt, M., Nyakoe, N., Muringo, L., Ogutu, B., Waitumbi, J. N., and Ockenhouse, C. F. (2011) Development of a highly sensitive genus-specific quantitative reverse transcriptase real-time PCR assay for detection and quantitation of plasmodium by amplifying RNA and DNA of the 18 S rRNA genes. J. Clin. Microbiol. 49, 2946-2953

49. Adams, M., Joshi, S. N., Mbambo, G., Mu, A. Z., Roemmich, S. M., Shrestha, B., Strauss, K. A., Johnson, N. E., Oo, K. Z., Hlaing, T. M., Han, Z. Y., Han, K. T., Thura, S., Richards, A. K., Huang, F., Nyunt, M. M., and Plowe, C. V. (2015) An ultrasensitive reverse transcription polymerase chain reaction assay to detect asymptomatic low-density Plasmodium falciparum and Plasmodium vivax infections in small volume blood samples. Malar J 14, 520

50. Habibi, G. (2012) Phylogenetic Analysis of Theileria annulata Infected Cell Line S15 Iran Vaccine Strain. Iran J Parasitol 7, 73-81 
bioRxiv preprint doi: https://doi. org/10.1101/2021.01.12 426319. this version posted January 14,2021 . The copyright holder for this preprint (which was not certified by peer review) is the author/funder, who has granted bioRxiv a license to display the preprint in perpetuity. It is made available under aCC-BY 4.0 International license.

\section{Tables}

653 Table 1. Sample summary.

\begin{tabular}{|c|c|c|c|}
\hline Origin & Number & Genera & Nucleic acids analyzed \\
\hline Cambodia & 265 individuals & Anopheles & DNA \\
\hline Guinea and Mali & 665 individuals & Anopheles & DNA/RNA \\
\hline Maryland, USA & 25 pools & $\begin{array}{l}\text { Aedes, Anopheles, Culex, } \\
\text { Culiseta, Ochlerotatus, } \\
\text { Psorophora, Uranotaenia }\end{array}$ & DNA/RNA \\
\hline
\end{tabular}


Table 2. Primers used.

\begin{tabular}{|c|c|c|c|c|}
\hline Taxon targeted & Name & Forward Primer & Reverse Primer & $\begin{array}{l}\text { Amplicon } \\
\text { Length }\end{array}$ \\
\hline Apicomplexa (primers A) (23) & Apicomp18S_365-613 & GACCTATCAGCTTTCGACGG & CCCTCCAATTGWTACTCTGGR & $244-248$ \\
\hline Apicomplexa (primers B) (23) & Plasmo18S_883-1126 & TGYGTTTGAATACTAYAGCATGG & TCTGATCGTCTTCACTCCCTT & $228-244$ \\
\hline Apicomplexa (primers C) (23) & Eimeriorina18S_302-730 & TTGGMCTACCGTGGCARTGA & TCAAGGCAAHWGCCTGCTT & $420-470$ \\
\hline Kinetoplastida (23) & Kineto_18S4 & AAATTAAACCGCACGCTCCA & GCAAACGATGACACCCATGA & $250-300$ \\
\hline Microsporidia (23) & Microsporidia_18S & BCAGGTTGATTCTGCCTGACR & ACCAGWCTTGCCCTCCARTT & $370-440$ \\
\hline Parabasalia (23) & Parab18S_288-654 & TAGGCTATCACGGGTAACGG & GCGTCCTGATTTGTTCACAG & $326-364$ \\
\hline Platyhelminthes (23) & Platy_18S3 & CAATTGGAGGGCAAGTCTGG & TGCTTTCGCWKTAGTTTGTCTG & $350-550$ \\
\hline Nematode (primers A) (23) & Spirur18S_1435-1858 & CACCCGTGAGGATTGACAG & CGATCACGGAGGATTTTTCAA & $320-335$ \\
\hline Nematode (primers B) (23) & Spirurida_18S2 & CGTCATTGCTGCGGTTAAAA & CCGTCCTTCGAACCTCTGAC & $380-410$ \\
\hline Nematode (primers C) (23) & Tricho_18S2 & AGTGGAGCATGCGGCTTAAT & TGCAATTCCCTRTCCCAGTC & $380-440$ \\
\hline Flavivirus (25) & FlaviallS_FlaviallAS2 & TACAACATGATGGGGAARAGAGARAA & GTGTCCCAGCCNGCKGTGTCATCWGC & $263-266$ \\
\hline Theileria (50) & Theileria & GGCGGCGTTTATTAGACC & TCAATTCCTTTAAAGTTTCAGCC & 894-1045 \\
\hline Filarial (long range PCR) & Filarial & TTCGTCGTGAGACAGAGCGG & AGGCCATTGACGGATGGTTTGTAC & 3500 \\
\hline
\end{tabular}

657 
bioRxiv preprint doi: https://doi.org/10.1101/2021.01.12.426319; this version posted January 14,2021. The copyright holder for this preprint

(which was not certified by peer review) is the author/funder, who has granted bioRxiv a license to display the preprint in perpetuity. It is made available under aCC-BY 4.0 International license.

658 Table 3. Genera amplified from each group of samples.

\begin{tabular}{|c|c|c|c|c|c|}
\hline \multirow{2}{*}{$\frac{\text { Target }}{\text { Apicomplexa }}$} & \multirow[t]{2}{*}{ Genus } & \multicolumn{3}{|c|}{ Maryland } & \multirow[t]{2}{*}{ Identity } \\
\hline & & 21 & 31 & 17 & \\
\hline & Ascogregarina & 2 & 0 & 0 & $100.00 \%$ \\
\hline & Babesia & 1 & 0 & 0 & $100.00 \%$ \\
\hline & Cryptosporidium & 0 & 1 & 0 & $92.08 \%$ \\
\hline & Hepatocystis & 1 & 0 & 0 & $85.45 \%$ \\
\hline & Hepatocystis/Plasmodium & 4 & 0 & 0 & $93.50 \%$ \\
\hline & Paraschneideria & 1 & 0 & 0 & $91.63 \%$ \\
\hline & Plasmodium & 20 & 8 & 2 & $82.02 \%-100.00 \%$ \\
\hline & Theileria & 7 & 22 & 15 & $99.10 \%-100.00 \%$ \\
\hline \multirow[t]{11}{*}{ Kinetoplastida } & & 22 & 0 & 1 & \\
\hline & Angomonas/Crithidia & 5 & 0 & 0 & $99.56 \%-100.00 \%$ \\
\hline & Blastocrithidia & 1 & 0 & 0 & $98.27 \%$ \\
\hline & Blastocrithidia/Crithidia/Leptomonas/Wallaceina & 4 & 0 & 0 & $100.00 \%$ \\
\hline & Blechomonas & 2 & 0 & 0 & $90.27 \%-91.44 \%$ \\
\hline & Crithidia & 15 & 0 & 0 & $99.13 \%-100.00 \%$ \\
\hline & Crithidia/Trypanosomatidae & 6 & 0 & 0 & $100.00 \%$ \\
\hline & Paratrypanosoma & 2 & 0 & 0 & $94.86 \%$ \\
\hline & Strigomonas & 8 & 0 & 1 & $96.89 \%-100.00 \%$ \\
\hline & Trypanosoma & 22 & 0 & 0 & $82.70 \%-100.00 \%$ \\
\hline & Zelonia & 1 & 0 & 0 & $98.71 \%$ \\
\hline \multirow[t]{6}{*}{ Flaviviridae } & & 7 & 4 & 0 & \\
\hline & Aedes flavivirus/Calbertado virus & 1 & 0 & 0 & $74.26 \%$ \\
\hline & Anopheles flavivirus & 0 & 3 & 0 & $87.20 \%-99.06 \%$ \\
\hline & Calbertado virus & 7 & 0 & 0 & $71.09 \%-74.26 \%$ \\
\hline & Culex flavivirus & 0 & 1 & 0 & $99.06 \%$ \\
\hline & Nienokoue virus & 1 & 0 & 0 & $72.99 \%$ \\
\hline \multirow[t]{11}{*}{ Microsporidia } & & 22 & 72 & 13 & \\
\hline & Agglomerata & 0 & 0 & 3 & $96.23 \%-96.52 \%$ \\
\hline & Amblyospora & 2 & 0 & 0 & $94.41 \%$ \\
\hline & Andreanna & 1 & 0 & 0 & $76.01 \%$ \\
\hline & Culicospora & 1 & 6 & 0 & $99.70 \%-100.00 \%$ \\
\hline & Encephalitozoon & 0 & 6 & 0 & $100.00 \%$ \\
\hline & Hazardia & 0 & 1 & 0 & $97.08 \%$ \\
\hline & Microsporidium & 7 & 34 & 0 & $88.29 \%-97.31 \%$ \\
\hline & Parathelohania & 5 & 28 & 10 & $91.27 \%-100.00 \%$ \\
\hline & Senoma & 0 & 0 & 3 & $94.20 \%$ \\
\hline & Takaokaspora & 14 & 0 & 0 & $94.61 \%-94.94 \%$ \\
\hline \multirow[t]{12}{*}{ Nematoda } & & 19 & 33 & 10 & \\
\hline & Abursanema & 0 & 1 & 0 & $95.34 \%$ \\
\hline & Acanthocheilonema & 3 & 13 & 0 & $100.00 \%$ \\
\hline & Aproctella & 2 & 0 & 0 & $100.00 \%$ \\
\hline & Aproctella/Setaria & 1 & 0 & 3 & $99.64 \%$ \\
\hline & Auanema & 0 & 1 & 0 & $98.21 \%$ \\
\hline & $\begin{array}{l}\text { Breinlia/Dipetalonema/Dirofilaria/ } \\
\text { Onchocerca/Pelecitus/Setaria }\end{array}$ & 0 & 0 & 6 & $99.64 \%$ \\
\hline & Caenorhabditis & 0 & 1 & 0 & $100.00 \%$ \\
\hline & Cercopithifilaria & 2 & 0 & 0 & $100.00 \%$ \\
\hline & Choriorhabditis & 1 & 0 & 0 & $99.71 \%$ \\
\hline & Dipetalonema & 4 & 3 & 0 & $98.68 \%-99.20 \%$ \\
\hline & Dipetalonema/Loa & 0 & 7 & 0 & $100.00 \%$ \\
\hline
\end{tabular}




\begin{tabular}{|c|c|c|c|c|c|}
\hline & Dipetalonema/Loa/Loxodontofilaria/Yatesia & 1 & 0 & 0 & $99.64 \%$ \\
\hline & Dipetalonema/Loa/Madathamugadia & 0 & 2 & 0 & $99.64 \%$ \\
\hline & Dipetalonema/Loa/Onchocerca & 0 & 2 & 0 & $99.64 \%$ \\
\hline & Dipetalonema/Loa/Pelecitus & 0 & 1 & 0 & $99.64 \%$ \\
\hline & Dipetalonema/Loa/Setaria & 2 & 0 & 6 & $99.64 \%$ \\
\hline & Dirofilaria & 1 & 0 & 0 & $100.00 \%$ \\
\hline & Dirofilaria/Onchocercidae & 1 & 0 & 0 & $99.44 \%$ \\
\hline & Elaeophora/Setaria & 1 & 0 & 0 & $99.44 \%$ \\
\hline & Filarioidea & 5 & 3 & 0 & $100.00 \%$ \\
\hline & Loxodontofilaria & 1 & 0 & 0 & $100.00 \%$ \\
\hline & Loxodontofilaria/Setaria & 0 & 0 & 5 & $99.64 \%$ \\
\hline & Madathamugadia/Setaria & 0 & 0 & 6 & $99.64 \%$ \\
\hline & Onchocerca/Setaria & 0 & 0 & 6 & $99.64 \%$ \\
\hline & Setaria & 13 & 13 & 10 & $98.94 \%-100.00 \%$ \\
\hline & Trichuris & 0 & 1 & 0 & $99.77 \%$ \\
\hline & Yatesia & 8 & 0 & 0 & $100.00 \%$ \\
\hline \multirow[t]{5}{*}{ Parabasalia } & & 0 & 4 & 1 & \\
\hline & Tetratrichomonas & 0 & 3 & 0 & $99.69 \%-100.00 \%$ \\
\hline & Trichomitus & 0 & 0 & 1 & $98.68 \%$ \\
\hline & Trichomonas & 0 & 1 & 0 & $99.34 \%$ \\
\hline & Tritrichomonas & 0 & 1 & 0 & $94.75 \%$ \\
\hline \multirow[t]{5}{*}{ Platyhelminthes } & & 3 & 4 & 3 & \\
\hline & Haematoloechus & 3 & 0 & 0 & $98.68 \%$ \\
\hline & Pleurogenes/Pleurogenoides & 0 & 0 & 1 & $94.93 \%$ \\
\hline & Pleurogenoides & 0 & 0 & 3 & $95.16 \%-95.37 \%$ \\
\hline & Schistosoma & 0 & 4 & 0 & $92.05 \%-100.00 \%$ \\
\hline
\end{tabular}

Figure 1. Phylogenetic analysis of flavivirus sequences amplified from mosquitoes. The neighbor-

662 joining tree shows the relationships between the flavivirus sequences amplified from mosquito pools

663 from Maryland (red circles) and from individual African mosquitoes (blue triangles). Phylogenetic tree

664 without compressed branch available in Supplemental Figure 2.

Figure 2. Phylogenetic analysis of Theileria sequences amplified from Cambodian and African

667 Theileria sequences amplified from samples positive by high-throughput sequences and those from 668 known Theileria species deposited in NCBI. Sequences amplified from Cambodian mosquitoes are 669 indicated in green circles, those amplified from African mosquitoes in red squares. 
670 Figure 3. Phylogenetic analysis of unknown filarial worm sequences amplified from Guinean

671 mosquitoes. The neighbor-joining tree shows the relationships between annotated filarial worm

672 sequences and a $3.5 \mathrm{~kb}$ sequence amplified from two African mosquitoes (red squares) positive for

673 filarial worms and sequenced using PacBio chemistry.

674 Figure 4. Comparison of the number of reads obtained for different taxa from matched DNA and cDNA

675 samples derived from Maryland mosquito pools.

676 Each panel represents results from one primer set and each pair of points connected by a line shows the

677 number of reads matching a single species detected in both the DNA (left) and RNA (right) from the

678 same sample. For five primers (red asterisks), the RNA samples yield significantly more reads than the

679 matching DNA samples ( $p<0.05$, Bonferroni-corrected pairwise t-tests).

680

681 


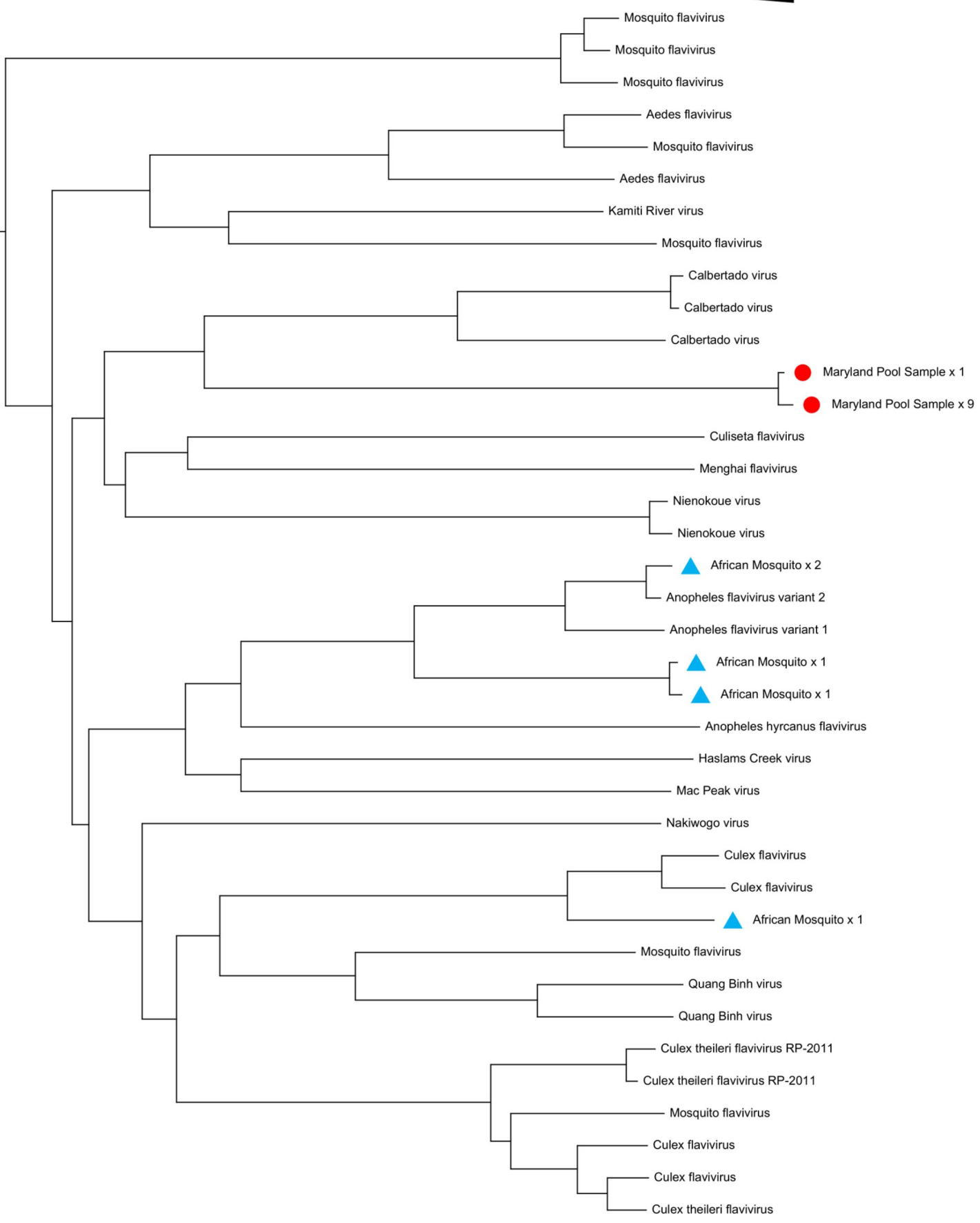




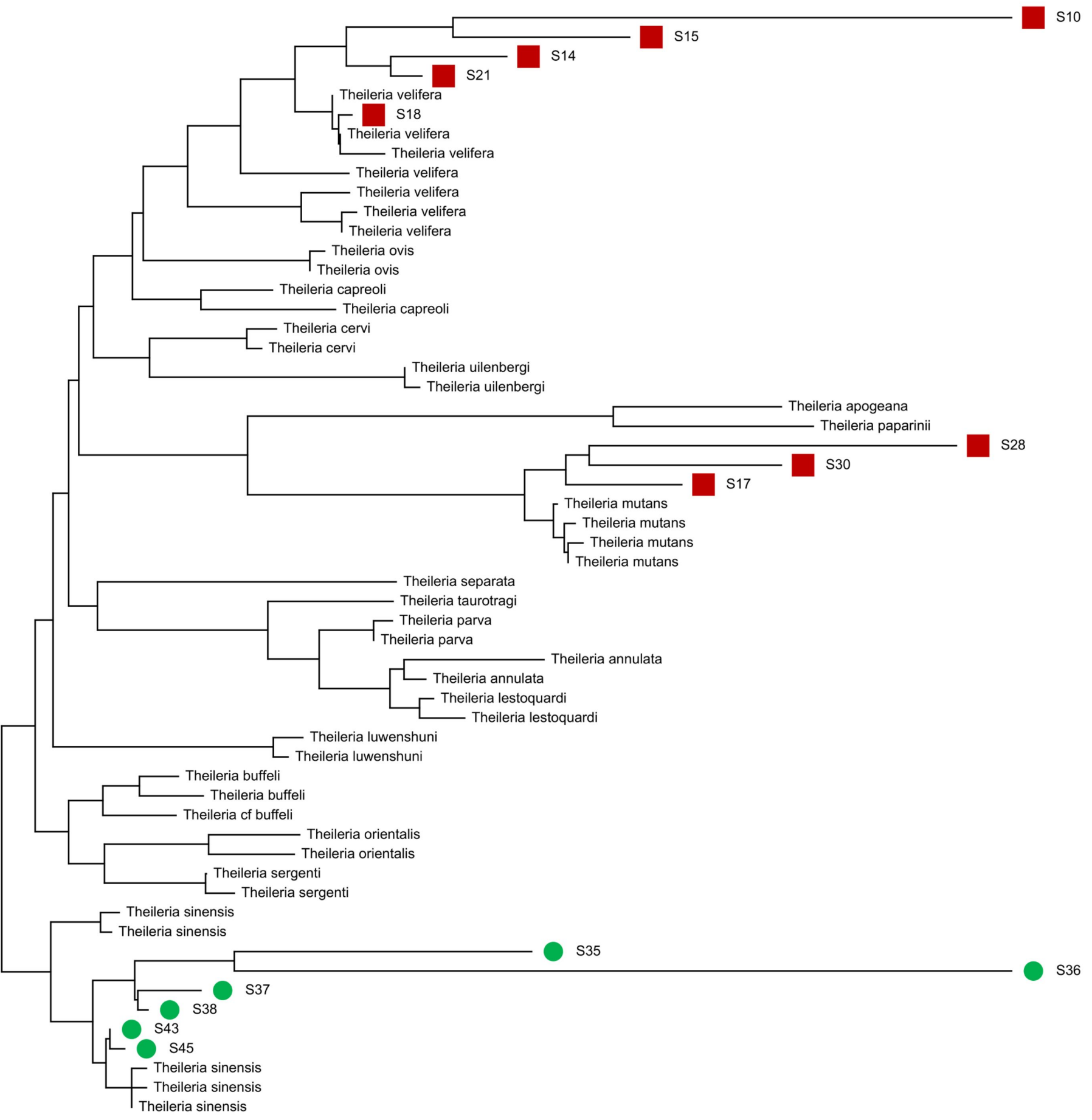




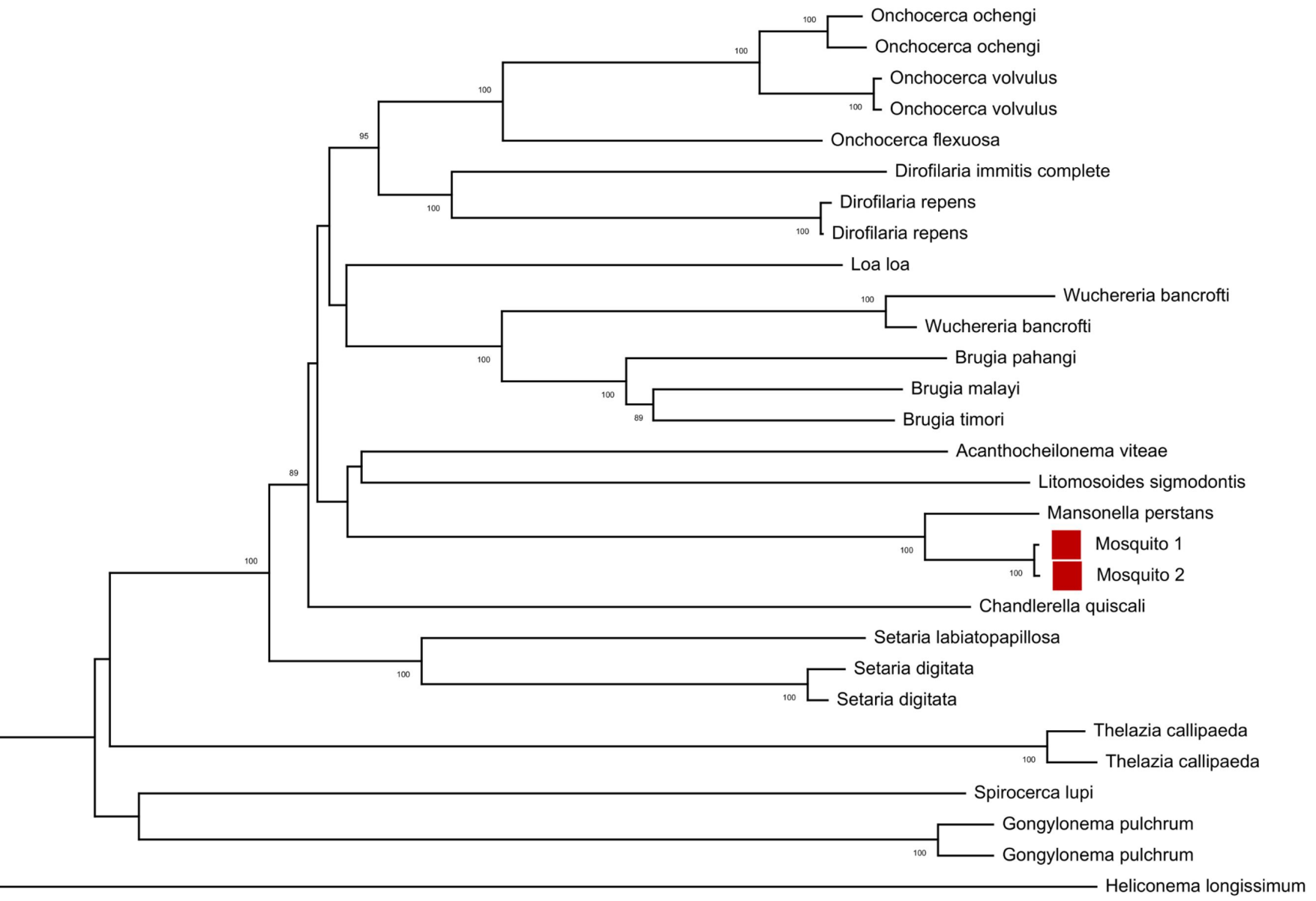




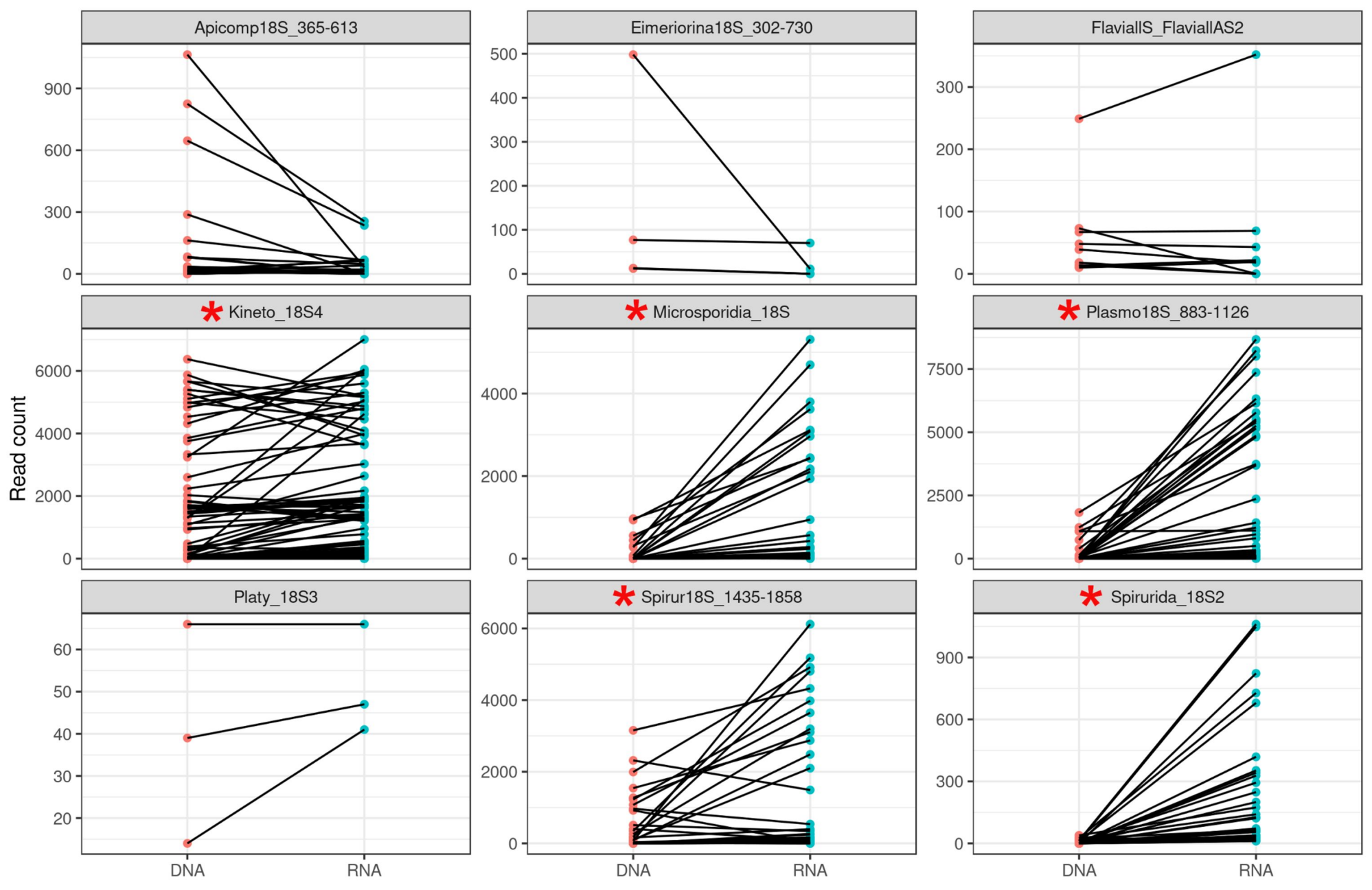

